\title{
Is there a new finding added to the fibromyalgia syndrome?
}

\author{
Banu Sarifakioglu ${ }^{1}$, Aliye Yildirim Guzelant ${ }^{1}$, Seref Alpsoy ${ }^{2}$, \\ Birol Topcu ${ }^{3}$, Cuneyt Unsal ${ }^{4}$, Nilay Sahin ${ }^{5}$ \\ ${ }^{1}$ Deparment of Physical Therapy and Rehabilitation, Namik Kemal University Faculty of Medicine, Tekirdag, Turkey; \\ ${ }^{2}$ Deparment of Cardiology, Namik Kemal University Faculty of Medicine, Tekirdag, Turkey; \\ ${ }^{3}$ Deparment of Biostatistics, Namik Kemal University Faculty of Medicine, Tekirdag, Turkey; \\ ${ }^{4}$ Department of Psychiatry, Namik Kemal University Faculty of Medicine, Tekirdag, Turkey; \\ ${ }^{5}$ Deparment of Physical Therapy and Rehabilitation, Balıkesir University Faculty of Medicine, Balikesir, Turkey
}

\begin{abstract}
OBJECTIVE: The aim of this study is to examine depression and anxiety related arrhytmia risk in fibromyalgia syndrome (FMS).

METHODS: Fifty-nine patients with the diagnosis of FMS and 20 control participants were included in the study. Fibromyalgia Impact Questionnaire (FIQ), Visual Pain Scale (VPS) surveys were applied to determine the severity of the disease. Beck Anxiety (BAS) and Beck Depression scales (BDS) were applied to all participants. Electrocardiograms were obtained from all participants. P-wave dispersions $(\mathrm{Pd})$ were estimated to determine the risk of the atrial arrhythmia, and QT wave dispersion (QTd) and corrected QT(QTdd) values were used to predict the risk of ventricular arrhythmia.
\end{abstract}

RESULTS: BAS and BDS results were significantly higher in the patient group compared to the control group $(\mathrm{p} \square$ 0001). In the patient group, Pd was significantly longer $(\mathrm{p}=0.034)$. Other clinical, and demographic data did not differ significantly between groups.

CONCLUSION: In this study, the risk of arrhythmia in FMS was evaluated and increased Pd in patients with FMS compared to the control group was detected. This finding shows increased risk of atrial fibrilation (AF) in patients with FMS. If we consider that patients with fibromyalgia consist relatively of young patients together with the increased risk of AF with age, it is important to follow-up these patients in later ages for AF risk.

Key words: Anxiety, arrhythmia, depression, electrocardiogram, fibromyalgia

frequently seen in female population, and its prevalence has been reported as $3-5$ percent [1]. Its incidence increases with age, and peaks between 30 ,

Received: July 18, 2014 Accepted: September 01, 2014 Online: August 03, 2014

Correspondence: Nilay SAHIN. Balıkesir Universitesi Tıp Fakultesi, Fiziksel Tip ve Rehabilitasyon Anabilim Dalı, Balikesir, Turkey. 
and 50 years of age [2]. Its etiopathogenesis is not clear-cut [3]. FMS patients also suffer from pains, sleep disorders, lassitude, and anxiety problems [4]. The disease has common characteristics with depression, and their clinical findings are alike. Some patients have both of these diagnoses. Besides antidepressants have a greater place in their treatment [5]. It has been asserted that psychogenic factors (depression, and anxiety) can be associated with cardiac pathologies which can increase disease recurrence, and mortality rates [6].

Autonomic nervous system which is a component of peripheral nervous system, is responsible for the regulation of vital parameters as blood pressure, heart rate, respiration, and body temperature [7]. In cases of stress, activation of sympathetic nervous system becomes more prominent, however long-lasting stress can not be tolerated which can increase the incidence of chronic diseases [7]. Chronic pain, and lassitude can accompany these diseases. As a consequence of all these factors, the assertion that excessive sympathetic activation can be a place in the pathogenesis of chronic pain, and lassitude has been more strongly emphasized [8]. In cases of sympathetic hyperactivation and/or parasympathetic dysfunction, the body can not tolerate excessive stress which can result in emergence of lassitude, rigidity, tender points, intolerance to exercise, and sleep disorders [7, 9]. In addition, it has been recognized that pathological changes in sympathetic/parasympathetic activities can induce various types of arrhytmias [10].

In the etiopathogenesis of FMS, dysfunction of autonomic nervous system (ANS) can play a role [11]. In FMS, both pathways (sympathetic, and parasympathetic) of autonomic nervous system are affected in various degrees [11]. As has been reported, blockage of stellar ganglion with administration of bupivacaine, resting pain, and the number of trigger points decreased [12]. Autonomic nervous system dysfunction accounts for accompanying sleep disorder, anxiety, Raynaud phenomenon, Sicca symptoms, and irritable colon [11].

The risk of atrial fibrillation (AF) due to activation of parasympathetic nervous system (PNS) is already known [13]. Similarly, sympathetic ner- vous system ( $\mathrm{SNS}$ ) is thought to induce potential development of AF in some patients [13]. Still in a similar fashion, the association between ANS dysfunction with ventricular arrhytmias has been investigated. P-wave dispersion has been accepted as an indirect indicator of AF [13]. QT -wave dispersion is also considered as an indirect indicator of ventricular arrhytmias [13].

In this study, we aimed to determine the levels of depression, and anxiety in patients with FMS, and investigate whether these psychopathologies increase the risk of atrial and/or ventricular arrhytmias.

\section{MATERIALS AND METHODS}

The study was designed as a prospective, controlled clinical study. Female patients aged $20-55$ years consulted to our outpatient clinics of physical therapy, and rehabilitation with the diagnosis of FMS based on 2010 FMS criteria were enrolled in our study [14]. Patients with an established diagnosis of cardiac pathology (arrhytmia, valvular disease, myocardial infarction, heart failure, and rheumatic heart disease), thyroid dysfunction, malignancies, renal disease, major depression, bipolar disorder, and users of some drugs (beta blockers, calcium channel blockers or antiarrhytmic drugs) were excluded from the study. Local ethics committee approval was obtained for this study.

Whole blood counts, sedimentation rate, Creactive protein values, kidney, and liver function tests, serum electrolyte, and TSH levels were analysed. Patients with electrolyte disorders, hypo/ hyperthyroidism were excluded from the study. Demographic data, number of tender points, Symptom Severity Scale (SSS), and Widespread Pain Index (WPI) scores which were included in 2010 diagnostic criteria were recorded.

Age-matched otherwise healthy female individuals who consulted to the PTR outpatient clinics with complaints of joint pain, without established diagnoses of FMS, depression/anxiety, cardiac, thyroid, and renal disease comprised the control group.

\section{Clinical assessments}

Visual Pain Scale (VPS) was used to evaluate sever- 
ity of pain which was rated on a scale of 10 points ( 0 , no pain , and 10 , intolerable pain). Fibromyalgia Impact Questionnaire (FIQ) whose validity, and reliability of its Turkish version were performed was used to assess disease severity of FMS [15]. This scale measures 10 separate items including physical function, feeling good, inability to go to work, pain, fatigueness, morning fatigueness, stiffness, anxiety, and depression. Excluding feeling good item, lower scores indicate improvement or lesser severity of the disease. FIQ questionnaire is completed by the patient. Maximum score of each subheading can only be 10 points. Thus total maximum score amounts to 100 points. An average FMS patient scores 50 points, and severely affected FMS patients generally get more than 70 points.

To determine the presence, and level of depressive mood of the patients, Beck's Depression Scale (BDS) whose validity, and reliability of its Turkish version have been established was applied [16]. This scale consists a total of 21 items. Three points were assigned for the evaluation of each item. Maximum score is 63 points. Absence of depressive mood (013 pts), moderate (14-24 pts), and severe (>25 pts) depressive moods were evaluated as indicated.

In order to evaluate anxiety levels of the patients, Turkish version of the Beck's Anxiety Scale (BAS) with established validity, and reliability was used [17]. This scale consist of a total of 21 questions. Each question is rated on 3 points. Scores range between 0 , and 63 points. Total number of points indicate severity of anxiety experienced by the patient.

Patients of the control group were also evaluated using BAS, and BDS scale scores, and ECG examinations.

\section{Evaluation of risk of arrhytmia}

Patients evaluated in the PTR clinics were referred to the outpatient clinics of cardiology. Electrocardiograms (ECG) of the patients were obtained, and evaluated by the same physician (ŞA) blinded to the study population. Twelve -lead electrocardiograms were recorded at a velocity of ile $25 \mathrm{~mm} / \mathrm{sec}$ on a scale of $1 \mathrm{mV} / \mathrm{cm}$ using Schiller-U2 ECG machine (Schil- ler lnc., Baar, Switzerland). P waves, QT, and RR intervals were determined with standard measurement methods, and average of estimates from three ECG cycles was obtained. In all calculations of ECG leads, the beginning of $\mathrm{P}$ wave from the isoelectric line was accepted as the onset of $\mathrm{P}$ wave. Its end point was considered as the beginning of the isolectric line.

QT complex was considered as the interval from the QRS complex up to the end of $T$ wave.If the end point of the $T$ wave was not clear-cut, then intersection point between descending arm of the $T$ wave, and isoelectric line was accepted as the end point of $\mathrm{T}$ wave. Every maximum, and minimum value in 12-lead ECG were recorded to evaluate $\mathrm{P}$ wave, and QT dispersion values. Briefly, P dispersion $\left(\mathrm{P}_{\mathrm{d}}\right)$ can be indicated as the difference between maximum, and minimum $\mathrm{P}$ wave durations. For $\mathrm{P}_{\mathrm{d}}$, average duration of at least $3 \mathrm{P}$ waves in each derivation was calculated. The longest $\left(\mathrm{P}_{\max }\right.$ and the shortest $\left(\mathrm{P}_{\min }\right) \mathrm{P}$ waves were determined, and the difference between $\mathrm{P}_{\max }$ and $\mathrm{P}_{\text {min }}$ was estimated, and defined as $\mathrm{Pd}$ in milliseconds.

$\mathrm{P}_{\mathrm{d}}=\mathrm{P}_{\text {max }}-\mathrm{P}_{\text {min }}$.

In 12-lead ECG, the difference between the longest, and the shortest QT intervals was called QT dispersion $\left(\mathrm{QT}_{\mathrm{d}}\right)$ which demonstrates increased ventricular repolarization. QTmax, and QTmin signify the longest, and the shortest QT intervals respectively. Since only $\mathrm{QT}_{\mathrm{d}}$ remains inadequate in the evaluation of ventricular arrhytmia, in lieu of QT intervals, corrected $\mathrm{QT}\left(\mathrm{QT}_{\mathrm{dd}}\right)$ intervals were used. Rate-corrected QT intervals in msec were estimated using Bazett formula. This conventional correction procedure aims to eliminate dependence of QT on heart rate.

$$
\begin{aligned}
& \mathrm{QT}_{\mathrm{d}}=\mathrm{QT}_{\text {max }}-\mathrm{QT}_{\text {min }} \\
& \text { Bazett formula: } \mathrm{QT} \mathrm{T}_{\mathrm{dd}}=\mathrm{Qt}_{\mathrm{d}} / \sqrt{ }(\mathrm{RR})
\end{aligned}
$$

\section{Statistical analysis}

Normality of distribution of each group was tested using Shapiro-Wilks test. Variables with normal distribution were expressed as mean \pm standard deviation, and non-normal distribution as medians (minimum-maximum), respectively. Comparisons of variables with normal, and non-normal distribu- 
tion were performed using independent samples- $t$ test, and Mann-Whitney U-test, respectively. Correlations between variables were evaluated using Spearman's correlation coefficient. Statistically, $\mathrm{p}<0.05$ was considered to be significant.

\section{RESULTS}

A total of 59 patients, and 20 control subjects were enrolled in the study. A statistically significant difference was not found between the patient, and the control groups as for body mass indexes (BMIs), and ages of the patients, however educational levels of both groups differed statistically significantly. Educational level of the control group was relatively higher. Demographic data are summarized in Table 1 .

VAS scores which indicate patient's disease activity, in addition to number of tender points (TP), SSS, and WPI values are presented in Table $1 . \mathrm{Pa}$ tients' BAS, and BDS scale scores were found to be statistically significantly higher when compared with those of the control group (Table 1).

Pmax and $\mathrm{Pd}$ values of the patients were significantly higher than those of the control group.
However, a significant difference was not detected between $\mathrm{P}_{\text {min }}, \mathrm{QT}_{\mathrm{d}}$, and $\mathrm{QT} \mathrm{T}_{\mathrm{dd}}$ values.

Clinical scale scores, and EKG results are presented in Table 2.

Correlations between clinical scales, and ECG were examined, and positive correlations among FIQ, BAS, and BDS were detected $(\mathrm{p}<0.001$, $r=0.516 ; p<0.001$, and $r=0.485$, respectively). BAS scores correlated significantly with the number of tender points $(p=0.021, r=0.315)$. VAS scores were found to be significantly correlated with the number of tender points, SSS, and WPI scores. $(p<0.001$, $r=0.710 ; p<0.001, r=0.544 ; p<0.001, r=0.724$, respectively). While the number of tender points was positively correlated with SSS, WPI scores, $\mathrm{P}_{\max }$ and $\mathrm{P}_{d}$ values $(\mathrm{p}=0.003, \mathrm{r}=0.400 ; \mathrm{p}<0.001$, $r=0.567 ; p=0.004, r=0.390 ; p=0.032, r=0.293$, respectively). SSS scores were significantly, and positively correlated with WPI, and $\mathrm{P}_{\min }(\mathrm{p}<0.001$, $r=0.450 ; p=0.010, r=0.347$, respectively).

\section{DISCUSSION}

In this study, we evaluated whether risk of arrhytmia increases in FMS, and in FMS patients increased

TABLE 1. Demographic data of the patient, and the control groups

\begin{tabular}{|c|c|c|c|}
\hline & Patient group & Control group & $\mathrm{p}$ \\
\hline & Mean \pm SD & Mean \pm SD & \\
\hline Age (years) & $42.32 \pm 7.80$ & $40.90 \pm 7.12$ & 0.474 \\
\hline BKI $\left(\mathrm{cm}^{2} / \mathrm{kg}\right)$ & $27.75 \pm 5.39$ & $26.93 \pm 3.60$ & 0.532 \\
\hline Duration of education (years) & $7.32 \pm 3.53$ & $10.40 \pm 3.97$ & 0.002 \\
\hline Duration of symptoms (months) & $87.30 \pm 90.92(3-360)$ & & \\
\hline VAS & $7.25 \pm 1.30$ & & \\
\hline Number of tender points & $13.88 \pm 2.63$ & & \\
\hline SSS & $8.40 \pm 1.77$ & & \\
\hline WPI & $13.08 \pm 3.63$ & & \\
\hline FIQ & $59.67 \pm 16.91$ & & \\
\hline BAS & $25.89 \pm 13.63$ & $13.75 \pm 7.19$ & \\
\hline$\square 0.001$ & & & \\
\hline BDS & $29.42 \pm 12.96$ & $13.95 \pm 7.17$ & \\
\hline$\square 0.001$ & & & \\
\hline
\end{tabular}


TABLE2. ECG data of the patient, and the control groups

\begin{tabular}{lccc} 
Variable & Patient group $(\mathrm{n}=59)$ & Control group $(\mathrm{n}=20)$ & $\mathrm{p}$ \\
\hline $\mathrm{P}_{\max }(\mathrm{msec})$ & $110(80-110)$ & $100(70-110)$ & $0.015^{*}$ \\
$\mathrm{P}_{\min }(\mathrm{msn})$ & $60(40-80)$ & $60(40-90)$ & 0.266 \\
$\mathrm{P}_{\mathrm{d}}(\mathrm{msec})$ & $45(30-70)$ & $39(20-60)$ & $0.034^{*}$ \\
$\mathrm{QT}_{\max }(\mathrm{msec})$ & $360(320-440)$ & $400(360-440)$ & 0.079 \\
$\mathrm{QT}_{\min }(\mathrm{msec})$ & $340(300-400)$ & $360(320-400)$ & 0.164 \\
$\mathrm{QT}_{\mathrm{d}}(\mathrm{msec})$ & $40(25-50)$ & $40(20-60)$ & 0.315 \\
$\mathrm{QTC}_{\text {max }}$ (msec) & $412.04 \pm 28.39$ & $417.89 \pm 22.85$ & 0.429 \\
$\mathrm{QTc}_{\min }(\mathrm{msec})$ & $372.12 \pm 24.91$ & $375.06 \pm 25.49$ & 0.665 \\
$\mathrm{QTC}_{\mathrm{d}}(\mathrm{msec})$ & $43(30-58)$ & $43(30-55)$ & 0.593 \\
\hline
\end{tabular}

Pd, P-wave dispersion; QTc: Corrected QT interval.

$\mathrm{Pd}$ values were detected in FMS patients when compared with the control group which demonstrates increased risk of arrhytmia in FMS patients relative to the control group. If we consider that FMS patients consist of relatively young patients, and increased risk of AF with advanced age, it is important to follow up these patients in their old age.

Neurohormonal factors, and autonomic dysfunction have been blamed in the etiopathogenesis of FMS [18]. In patients with FMS, it has been contemplated that together with autonomic activity, sustained, and variable heart rates also fluctuate [7]. With time fluctations in heart rates decrease, and autonomic system is dominated by the sympathetic system. Healthy adults respond in the same way, however this condition is not always as pronounced as in FMS patients [7]. It has been widely recognized that in FMS, sympathetic system is tonically active during the resting phase, but hyporeactive against physical stimuli [11]. If any other arrhytmogenic factor can not be identified, then autonomic dysfunction has been accepted as the cause of arrhytmias [18].

Many studies have investigated the correlations between FMS, and cardiac pathologies. Ablin et al. demonstrated the relationship between FMS, and coronary artery disease, and cardiac dysfunction in 43 patients with FMS [1]. Some authors reported increased mortality risk in FMS, but they couldn't reveal its etiopathogenesis [18]. In a study performed by Doğru et al, the investigators detected increased prevalence of supraventricular tachycardia (SVT) in 50 patients with FMS relative to normal healthy individuals [18]. In this study, they revealed that all SVT attacks developed during the night hours. They asserted that this phenomenon might be associated with increased sympathetic activity during night hours [18]. Increased risk of arrhytmia may be one of the probable etiological factors for this increased risk of arrhytmia.

$\mathrm{P}$-wave dispersion is considered as a specific, and sensitive marker of AF [19]. Besides, it can reportedly be an indicator for paroxysmal atrial fibrillation [20]. Dilaveris et al. detected significantly higher levels of $\mathrm{Pd}$ when compared with the healthy group. Still in the same study, the authors determined a $\mathrm{P}_{\mathrm{d}}$ value of $40 \mathrm{msec}$ is quiet sensitive (83\%), and specific (85\%) in the determination of AF risk with a $89 \%$ positive predictive value [21]. In another study, higher $\mathrm{P}_{\text {max }}$, and $\mathrm{P}_{\mathrm{d}}$ values were detected in patients with PAF relative to the healthy control group [20]. Still, in our study, $\mathrm{P}_{\mathrm{d}}$ value of the FMS group was determined as $45 \mathrm{msec}$ which demonstrates that FMS patients are under the risk of AF, and PAF.

In many studies performed, it has been found that anxiety detected in healthy individuals increased cardiac autonomic imbalance, and the risk of coronary artery disease [22]. It has been demon- 
strated that increased $\mathrm{QT}_{\mathrm{d}}$ value is associated with increased sympathetic or decreased parasympathetic modulation. $\mathrm{QT}_{\mathrm{d}}$ value is also a significant marker of cardiovascular mortality [23]. In our study, severe degrees of anxiety were detected in the FSM group relative to the control group without any evidence of increased risk of VF or VT which might be related to the scarcity of our patient population. Further studies with increased number of patients may demonstrate this correlation more clearly.

Autonomic nervous system innervates sinus, and atrioventricular nodes. Both of these nodes may be affected by autonomic stimuli. Both sympathetic, and parasympathetic stimuli can lead to the development of AF via different mechanisms [24]. If we consider the role of autonomic dysfunction in the etiopathogenesis of FMS, observance of arrhytmias in FMS should not be a surprisng finding. However this manifestation can be overlooked or neglected. Our study conveys importance, in that it revealed risk of $\mathrm{AF}$ in patients with FMS which was evidenced by the presence of $\mathrm{Pd}$ in these patients. However this assertion should be clarified with further studies involving larger patient population.

Scarcity of our patient population, and evaluation of arrhytmias using only ECG are major limitations of our study. Studies to be conducted with a larger patient, and control groups will provide more precise data. Besides, with Holter recording of alterations in patients' heart rhythms will enable us to obtain long-lasting information which will facilitate detection of arrhytmias.

In conclusion, our study determined the presence of increased risk of atrial arrhytmia in FMS disease. Atrial arrhytmias effect quality of life of the patients adversely, worsen preexisting disease, and also induce functional losses secondary to some ensuing complications. FMS patients should be followed up in consideration of this issue, and especially their risk for atrial fibrillation should be kept in mind. Further studies should be conducted on this issue.

Conflict of Interest: No conflict of interest was declared by the authors.

Financial Disclosure: The authors declared that this study has received no financial support.

\section{REFERENCES}

1. Ablin JN, Beilinson N, Aloush V, Elkayam O, Finkelstein A. Association between fibromyalgia and coronary heart disease and coronary catheterization. Clin Cardiol 2009;32:E7-11. CrossRef

2. Wolfe F, Anderson J, Harkness D, Bennett RM, Caro XJ, Goldenberg DL, et al. A prospective, longitudinal, multicenter study of service utilization and costs in fibromyalgia. Arthritis Rheum 1997;40:1560-70. CrossRef

3. Clauw DJ, Crofford LJ. Chronic widespread pain and fibromyalgia: what we know, and what we need to know. Best Pract Res Clin Rheumatol 2003;17:685-701. CrossRef

4. Branco JC, Bannwarth B, Failde I, Abello Carbonell J, Blotman F, Spaeth M, et al. Prevalence of fibromyalgia: a survey in five European countries. Semin Arthritis Rheum 2010;39:448-53.

5. Hassett AL, Cone JD, Patella SJ, Sigal LH. The role of catastrophizing in the pain and depression of women with fibromyalgia syndrome. Arthritis Rheum 2000;43:2493-500. CrossRef

6. Lespérance F, Frasure-Smith N, Talajic M, Bourassa MG. Fiveyear risk of cardiac mortality in relation to initial severity and one-year changes in depression symptoms after myocardial infarction. Circulation 2002;105:1049-53. CrossRef

7. Meeus M, Goubert D, De Backer F, Struyf F, Hermans L, Coppieters $\mathrm{I}$, et al. Heart rate variability in patients with fibromyalgia and patients with chronic fatigue syndrome: a systematic review. Semin Arthritis Rheum 2013;43:279-87. CrossRef

8. Martinez-Lavin M. Biology and therapy of fibromyalgia. Stress, the stress response system, and fibromyalgia. Arthritis Res Ther 2007;9:216. CrossRef

9. Furlan R, Colombo S, Perego F, Atzeni F, Diana A, Barbic F, et al. Abnormalities of cardiovascular neural control and reduced orthostatic tolerance in patients with primary fibromyalgia. J Rheumatol 2005;32:1787-93.

10. Aytemir K, Deniz A, Yavuz B, Ugur Demir A, Sahiner L, Ciftci $\mathrm{O}$, et al. Increased myocardial vulnerability and autonomic nervous system imbalance in obstructive sleep apnea syndrome. Respir Med 2007;101:1277-82. CrossRef

11. Kulshreshtha P, Gupta R, Yadav RK, Bijlani RL, Deepak KK. A comprehensive study of autonomic dysfunction in the fibromyalgia patients. Clin Auton Res 2012;22:117-22. CrossRef

12. Bengtsson A, Bengtsson M. Regional sympathetic blockade in primary fibromyalgia. Pain 1988;33:161-7. CrossRef

13. Podrid PJ, Kowney PR. Cardaic arrhythmia, mechanisms, diagnosis \& management. 2nd ed. Philadelphia: Lippincott Williams $\&$ Williams; 2001. p. 111-651.

14. Wolfe F, Clauw DJ, Fitzcharles MA, Goldenberg DL, Häuser W, Katz RS, et al. Fibromyalgia criteria and severity scales for clinical and epidemiological studies: a modification of the ACR Preliminary Diagnostic Criteria for Fibromyalgia. J Rheumatol 2011;38:1113-22. CrossRef

15. Sarmer S, Ergin S, Yavuzer G. The validity and reliability of the Turkish version of the Fibromyalgia Impact Questionnaire. Rheumatol Int 2000;20:9-12. CrossRef 
16. Hisli N. Beck Depresyon Envanterinin üniversite öğrencileri için geçerliği, güvenirliği. Psikoloji Dergisi 1989;7:3-13.

17. Ulusoy M, Sahin NH, Erkmen H. Turkish version of the Beck Anxiety Inventory: psychometric properties. Journal of Cognitive Psychotherapy 1998;1:163-72.

18. Dogru MT, Aydin G, Tosun A, Keleș I, Güneri M, Arslan A, et al. Correlations between autonomic dysfunction and circadian changes and arrhythmia prevalence in women with fibromyalgia syndrome. Anadolu Kardiyol Derg 2009;9:110-7.

19. Dilaveris PE, Gialafos JE. P-wave dispersion: a novel predictor of paroxysmal atrial fibrillation. Ann Noninvasive Electrocardiol 2001;6:159-65. CrossRef

20. Aytemir K, Ozer N, Atalar E, Sade E, Aksöyek S, Ovünç K, et al. $\mathrm{P}$ wave dispersion on 12-lead electrocardiography in patients with paroxysmal atrial fibrillation. Pacing Clin Electrophysiol 2000;23:1109-12. CrossRef

21. Dilaveris PE, Gialafos EJ, Sideris SK, Theopistou AM, Andrikopoulos GK, Kyriakidis M, et al. Simple electrocardiographic markers for the prediction of paroxysmal idiopathic atrial fibrillation. Am Heart J 1998;135:733-8. CrossRef

22. Kawachi I, Colditz GA, Ascherio A, Rimm EB, Giovannucci E, Stampfer MJ, et al. Prospective study of phobic anxiety and risk of coronary heart disease in men. Circulation 1994;89:1992-7.

23. Okin PM, Devereux RB, Howard BV, Fabsitz RR, Lee ET, Welty TK. Assessment of QT interval and QT dispersion for prediction of all-cause and cardiovascular mortality in American Indians: The Strong Heart Study. Circulation 2000;101:61-6.

24. Özin B. Otonom sinir sistemi ve aritmiler. Turk Kardiyol Dern Ars 1999;27:701-7. 